\title{
FACTORS ASSOCIATED WITH ANENCEPHALUS AND SPINA BIFIDA IN BELFAST
}

\author{
J. H. ELWOOD AND N. C. NEVIN \\ Department of Social and Preventive Medicine and Human Genetics Unit, Department of Medical Statistics, \\ The Queen's University of Belfast, Northern Ireland
}

A high incidence of major malformations of the central nervous system has been reported from both Northern Ireland (Stevenson, Johnston, Stewart, and Golding, 1966) and the Irish Republic (Coffey and Jessop, 1957). These studies, however, were based on hospital births only, leaving some doubt as to whether these high frequencies are real or partly due to preselection of such cases for management in specialist obstetric units. Up to 1968, only one Irish community study based on complete ascertainment of the major central nervous system malformations occurring in a defined population-Belfast during one year, 1957-had been conducted (Stevenson and Warnock, 1959). Thus, further investigations were initiated in Northern Ireland, and to date some of the findings of a survey into anencephalus in Belfast have been presented (Elwood and Warnock, 1969; Elwood, 1970a; Elwood and MacKenzie, 1971). The current study is the first report of a multidisciplinary investigation into spina bifida in Belfast and also includes some considerations of anencephalus not previously reported.

\section{Population Studied}

Approximately 8,000 births occur annually in Belfast (1966 population census, 398,405 persons). Compared with other large urban areas in the United Kingdom, this city has a high stillbirth rate, 21 per 1,000 total births in 1968, and a high infant mortality rate, 31 per 1,000 livebirths (Elwood and Pemberton, 1971).

Since 1957 a register containing biosocial data on all (live and still) births to residents has been maintained by the Belfast Health Department and the University Departments of Social and Preventive Medicine, and Medical Statistics (Stevenson and Warnock, 1959). These data now form part of the Northern Ireland Record Linkage Project (Cheeseman, 1968). The population studied included all stillbirths of 28 or more weeks' gestation and all livebirths irrespective of gestational age delivered to women resident within the statutory boundary of Belfast County Borough during the period from
1 January 1964 to 31 December 1968. Births to temporary residents and to non-residents admitted to hospitals within Belfast during this quinquennium were excluded. Some 41,351 total births were so defined and comprise the population at risk.

\section{ASCERTAINMENT}

This study began in 1969 and thus ascertainment was made retrospectively.

All cases of anencephalus, iniencephalus, exencephalus, and encephalocoele, occurring alone or in combination with one or more additional malformations including cases of anencephalus with spina bifida, were contained under the diagnosis of anencephalus. The group defined as spina bifida included meningocele, hydromeningocele, myelomeningocele, and syringomyelocele, occurring alone or in combination with hydrocephalus or other defects. Cases of spina bifida occulta and other minor lesions with or without neurological involvement were excluded.

Several sources of ascertainment were used. The primary source was the birth register combined with data relating to all stillbirths and infant deaths occurring in Belfast annually, collected in cooperation with the Maternal and Child Care Division (Warnock, 1969; Corbett, 1970) of the Municipal Health Department. The Registrar General's Office for Northern Ireland provided death certificate data on all deaths registered in Belfast County Borough in which anencephalus or spina bifida was mentioned. Additional sources were utilized to ascertain the surviving cases of spina bifida and also to cross-check information on the children presumed dead from the above-mentioned information: records of the voluntary Notification for Congenital Malformations System in Northern Ireland (Elwood, 1970b, 1972a), data relating to patients referred to the Medical Genetic Unit for genetic counselling, necropsy reports, and records of hospitals in the Belfast area were searched. The final step consisted of linking the affected births, using Christian names and surname, address, and date of 
birth, to the register of the birth population at risk. Cases not successfully matched were omitted. Because of the obvious and striking macroscopic appearance of the defects under consideration, the complete fatality of one, anencephalus, and the use of several sources of data collection we are of the opinion that ascertainment is fairly complete. Omission, if present, probably relates to a small number of spina bifida survivors who have remained undetected by the local authority medical and ancillary staffs and by our own enquiries.

\section{Results}

\section{INCIDENCE}

The 41, 351 total births comprising the population at risk were followed up until each resulted in either death (stillborn or infant death) or survival at the age when ascertained (from 1 to 5 years). Of this Belfast quinquennial cohort 1964-68, 151 (41 males and 110 females) had anencephalus, 185 (76 males and 109 females) had spina bifida, and there were 24 ( 5 males and 19 females) cases of anencephalus with spina bifida.

The incidence of anencephalus, which includes the group having anencephalus with spina bifida, averaged $4 \cdot 2$ and of spina bifida $4 \cdot 5$ per 1,000 total births (Table I). Spina bifida, therefore, appears to be slightly more common than anencephalus although the two rates are not significantly different. We have not yet separated, to our satisfaction, cases of true congenital hydrocephalus from hydrocephalus secondary to other pathology and have, therefore, excluded hydrocephalus from the present study. However, it seems clear that the incidence of neural tube defects is of the order of $1 \%$ or more of all births in Belfast at the present time. This frequency is the highest in the world so far reported for a whole population and exceeds that observed in another high incidence area of the United Kingdom, namely, South Wales (Laurence, Carter, and David, 1968).
Data relating to secular variations in the incidence $:$ of anencephalus indicate that such changes vary 3 within and between populations. The rate in $\stackrel{\mathbb{Q}}{\circ}$ Scotland (Leck and Rogers, 1967) and in Birmingham (Leck, 1966) has risen and fallen twice in the last $\stackrel{\vec{\rho}}{\rightarrow}$ 30 years, whilst in Belfast (Elwood, 1970a) there has been a small increase since 1950. Changes in the 흠 incidence of spina bifida appear to follow closely $\frac{\bar{m}}{\frac{1}{6}}$ those of anencephalus, but in some years one defect $\stackrel{\nabla}{\vec{\alpha}}$ may be more common than the other and vice versa.

\section{Seasonal Variation}

A study of the monthly numbers of cases of $\stackrel{\omega}{\mathscr{S}}$ anencephalus and spina bifida showed that these two observed distributions did not differ significantly $\stackrel{\overbrace{}}{\sim}$ from each other. Variation by season was then examined by comparing monthly and quarterly iv incidence rates and the frequencies in the winter and $\omega$ summer months (Table II). There was for both 을 defects a winter excess with a maximum in January when the rate was $11 \cdot 25$ per 1,000 total births 3 (anencephalus $4 \cdot 62$, spina bifida $6 \cdot 63$ ). The seasonal trend was more marked for fatal spina bifida births $\overrightarrow{0}$ than for those who survived. There was no definie cे seasonal variation in the monthly incidence anencephalic births. This contrasts with the signifis: cant winter excess found in the larger series of 397 cases in Belfast, 1956-66, previously reported (Elwood, 1970a). The current findings may be due $\frac{}{\Phi}$ in part to smaller numbers or, as seems more likely, to the fact that the variation by season in the incidence of neural tube defects appears to change over a period of years as well as varying from place to place. The monthly trends in Scottish anencephalic stillbirths, 1938-58, showed a definite decrease during $\stackrel{\mathbb{\Omega}}{\circ}$ May and August, but more recently, during the period 1959-63, this trough has been replaced by a 3 rise in incidence from March with a plateau through until August (Leck and Record, 1966). A similar $\frac{O}{3}$ phenomenon seems to have occurred in Belfast; the

TABLE I

POPULATION STUDIED-NUMBERS AND INCIDENCE PER 1,000 TOTAL BIRTHS, BELFAST COUNTY BOROUGH

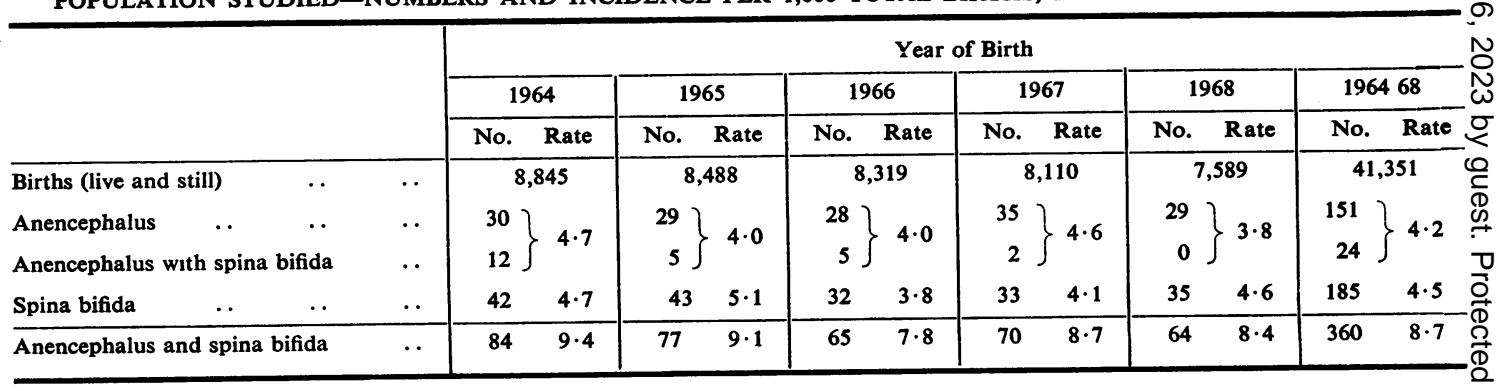


TABLE II

SEASONAL INCIDENCE PER 1,000 TOTAL BIRTHS

\begin{tabular}{|c|c|c|c|c|c|c|c|c|c|}
\hline & & & & & \multirow{2}{*}{$\begin{array}{c}\text { Incidence } \\
\text { of } \\
\text { Anencephalus }\end{array}$} & \multicolumn{3}{|c|}{ Incidence of Spina Bifida } & \multirow{2}{*}{$\begin{array}{c}\text { Incidence } \\
\text { of } \\
\text { Both Defects }\end{array}$} \\
\hline \multicolumn{5}{|c|}{ Month of Birth } & & Fatal* & Non-fatal & Total & \\
\hline $\begin{array}{l}\text { January-Ma } \\
\text { April-June } \\
\text { July-Septem } \\
\text { October-De }\end{array}$ & $\begin{array}{l}\mathrm{h} \\
\mathrm{m} \\
\text { mber }\end{array}$ & $\begin{array}{l}\ddot{*} \\
\ddot{*} \\
\cdots\end{array}$ & $\begin{array}{l}\cdots \\
\cdots \\
\cdots\end{array}$ & $\begin{array}{l}\cdots \\
\cdots \\
\cdots\end{array}$ & $\begin{array}{l}3 \cdot 74 \\
2 \cdot 77 \\
5 \cdot 68 \\
4 \cdot 82\end{array}$ & $\begin{array}{l}3 \cdot 74 \\
2 \cdot 31 \\
2 \cdot 31 \\
2 \cdot 71\end{array}$ & $\begin{array}{l}2 \cdot 10 \\
1 \cdot 94 \\
1 \cdot 73 \\
1 \cdot 10\end{array}$ & $\begin{array}{l}5 \cdot 84 \\
4 \cdot 25 \\
4 \cdot 04 \\
3 \cdot 81\end{array}$ & $\begin{array}{l}9 \cdot 58 \\
7 \cdot 02 \\
9 \cdot 72 \\
8 \cdot 63\end{array}$ \\
\hline All year & $\cdots$ & $\cdots$ & $\cdots$ & $\cdots$ & $4 \cdot 23$ & $2 \cdot 76$ & $1 \cdot 72$ & $4 \cdot 48$ & $8 \cdot 71$ \\
\hline Peak month & $\cdots$ & $\cdots$ & $\cdots$ & $\cdots$ & September & February & January & January & January \\
\hline$\frac{\text { Winter } * *}{\text { Summer }} \mathbf{R a}$ & & $\cdots$ & $\cdots$ & $\cdots$ & $1 \cdot 02$ & $1 \cdot 40$ & $0 \cdot 86$ & $1 \cdot 16$ & $1 \cdot 09$ \\
\hline
\end{tabular}

* Stillbirths plus deaths under 1 year

* Incidence in winter (defined as first plus last quarters) divided by incidence in summer (defined as second plus third quarters) of same year

1961-65 data exhibit a rise and subsequent plateau in incidence from April to June, followed by a trough in July, and finally a sustained increase in winter, reaching a maximum rate of $7 \cdot 87$ during October. The earlier quinquennium, 1956-60, did not show such a definite summer peak, although the high winter rate was present. The 1964-68 data suggest that the secondary peak in summer is becoming more dominant, while the main winter peak may be declining somewhat. In Belfast during the first half of the year from January to June, the incidence of spina bifida is consistently higher than that of anencephalus, but in the second half, from July onwards, the situation reverses, anencephalus becoming more frequent than spina bifida. The peak month (January) for spina bifida occurs in the first quarter of the year, agreeing with Guthkelch's (1962) findings of a high frequency in March in the Manchester area.

\section{Biosocial Factors}

Some $20 \%$ of anencephalics were liveborn, a higher proportion than in South Wales-3\% (Laurence et al., 1968), Scotland 7\%, or Birmingham $9 \%$ (Leck, 1966). The proportion of children with spina bifida who were born alive (83.7\%) also was greater than that found in South Wales (76.5\%).
Frequencies of each defect in single compared with multiple births showed a deficiency of spina bifida among the twins, although this difference was not significant. The 41,351 total births studied included 1,027 multiple births and, of these, five cases of neurological malformations were observed in four sets of twins; in one set, the first born had spina bifida with hydrocephalus and the second-born had anencephalus with spina bifida (Table III). The large excess of females having anencephalus $(26 \cdot 3 \%$ male ) and spina bifida ( $41 \cdot 1 \%$ male) in our series agrees with findings from several previous surveys.

The social class factor was examined, using the Registrar General's classification of occupations (General Register Office, 1966); illegitimate births were assigned on the basis of the father's occupation, if known, and if not, on that of the mother's father's occupation and status. There is a definite association between social class and both defects combined, the incidence in classes I and II being well below that in classes III, IV, and V (Table IV). Consideration of each defect separately shows that the social class trend for spina bifida is similar to that of anencephalus. Some previous studies found the highest incidence in the lowest social classes; nearly $10 \%$ of the fathers of anencephalics were unemployed in the Dublin survey (Coffey and Jessop, 1957), while in

TABLE III

TWINS, ONE OR BOTH HAVING A MAJOR MALFORMATION OF THE CENTRAL NERVOUS SYSTEM, BORN IN BELFAST

\begin{tabular}{l|l|l|l}
\hline $\begin{array}{c}\text { Year } \\
\text { of } \\
\text { Birth }\end{array}$ & $\begin{array}{c}\text { Sex of } \\
\text { Twin } \\
\text { Sets }\end{array}$ & \multicolumn{1}{|c|}{ First Born } & \multicolumn{1}{|c}{ Second Born } \\
\hline 1964 & MF & M, livebirth-normal & F, livebirth-anencephalus with spina bifida \\
1966 & FF & F, livebirth-anencephalus & F, livebirth-normal \\
1967 & FF & F, livebirth and later infant death-spina bifida & F, stillbirth-anencephalus with spina bifida \\
1968 & FF & F, livebirth-normal & F, livebirth-anencephalus \\
\hline
\end{tabular}


TABLE IV

DISTRIBUTION BY SOCIAL CLASS

\begin{tabular}{|c|c|c|c|c|c|c|c|c|c|}
\hline \multirow{2}{*}{\multicolumn{3}{|c|}{ Social Class }} & \multirow[b]{2}{*}{ No. of Total Births } & \multicolumn{2}{|c|}{ Anencephalus } & \multicolumn{2}{|c|}{ Spina Bifida } & \multicolumn{2}{|c|}{ Both Defects } \\
\hline & & & & No. & Rate & No. & Rate & No. & Rate \\
\hline I and II & .. & $\ldots$ & 3,563 & 9 & $2 \cdot 46$ & 10 & $2 \cdot 74$ & 19 & $5 \cdot 20$ \\
\hline III .. & .. & .. & 20,746 & 101 & $4 \cdot 87$ & 97 & $4 \cdot 67$ & 198 & $9 \cdot 54$ \\
\hline \multicolumn{3}{|c|}{ IV, V, and Unemployed } & 17,042 & 65 & $3 \cdot 81$ & 78 & $4 \cdot 58$ & 143 & $8 \cdot 39$ \\
\hline Total & .. & .. & 41,351 & 175 & $4 \cdot 23$ & 185 & $4 \cdot 48$ & 360 & $8 \cdot 71$ \\
\hline
\end{tabular}

Boston (Naggan and MacMahon, 1967) the pervalence rate for both anomalies in the poorest Irish Catholic families (5.4) was greater than the rate $(2.9)$ in those slightly better off (occupational classes 6-7 compared with 4-5 respectively, based on the classification by Warner, Meeker, and Eeles, 1957). In Belfast, however, the highest incidence was observed in social class III births. Why this should be so is not clear but this may relate to the rather broad nature of the classification used.

\section{Discussion}

This investigation demonstrates for the first time that the incidence of spina bifida in a whole population resident in Northern Ireland is very high (4.5 per 1,000 total births) and similar to the incidence of anencephalus $(4 \cdot 2$ per 1,000$)$ noted in Belfast during 1950-66 (Elwood, 1970a) and in the present study, covering the period 1964-68.

Regarding other Irish surveys, the investigations by Coffey and Jessop $(1955,1957)$ in Dublin and the study of perinatal mortality in Ireland, 1958-60 (Cahalane and Jessop, 1970), were based on hospital births only, but there have been three communitybased studies. Cahalane, Kennedy, McNicholl, and O'Dwyer (1965) collected data on all births in County Galway, 1958-60, which allow an estimate of 3.9 per 1,000 total births to be calculated for the incidence of anencephalus in this western area of the country; Spellman $(1969,1970)$ surveyed Cork City and County, 1962-66, and recorded an anencephalic rate of $2 \cdot 0$ and a spina bifida rate of $2 \cdot 4$; thirdly, and most recently, Coffey (1970) found a spina bifida rate of $4 \cdot 1$ per 1,000 deliveries based on all births in the 26 counties of the Irish Republic, 1961-62. Thus, although information regarding neurological malformations is incomplete, it now seems fairly clear that the incidence of anencephalus and probably also of spina bifida is high in most communities throughout Ireland (Elwood, 1970c) with the proviso that the surveys to date have been conducted in pre- $\frac{\text { क }}{\text { के }}$ dominantly industrial populations. An urban/rural $\stackrel{\odot}{\rightarrow}$ gradient with neural tube defects being more common in cities, of which there is some evidence (Edwards, 1958), might alter the picture as a large $\omega$ proportion of the present population of Ireland ${ }^{\omega}$ reside in rural areas.

In the United Kingdom several studies of fatal $\vec{z}$ neurological malformations have been made, using the stillbirth and infant death registrations tabulated by the Registrar General. In the Irish Republic, $\vec{\varphi}$ however, stillbirths are not legally required to registered, but instead they are notified under voluntary non-statutory system to the local Medicin Officer of Health. For this reason, the late fetal death returns tabulated by the Central Statistics Office, $\stackrel{0}{\varrho}$ Dublin, should be interpreted with caution if $\stackrel{\Phi}{\stackrel{\Phi}{ }}$ directly compared without some adjustment to the $\overrightarrow{\vec{B}}$ United Kingdom stillbirth registration data. Exami- $\frac{3}{3}$ nation of the geographical distribution of the proportions of anencephalics occurring as live or: stillborn in the 32 counties of Ireland showed that in some areas a majority were reported to have been $)$ born alive (Elwood, 1972b, 1973a). This was most common in counties where the total anencephalic 3 . rate (based on affected stillbirths plus infant deaths) was relatively low. Also, the frequencies in the six rural counties of Northern Ireland were in generalo higher than in several of the 26 counties comprising $>$ the Irish Republic. These findings may be variouslyo interpreted. The high proportion of anencephalics ${ }_{N}$. born alive suggests undernotification of affected. stillbirths in these areas or possibly cultural reasons $N$ might account for this difference in Irish medical ్ㅗ certification practice compared with elsewhere.o Alternatively, there may genuinely be reato variations in the incidence of anencephalus within Ireland but further ad hoc surveys, particularly in rural communities, are required before this can definitely be demonstrated. We note that Spellman'so figure of 2.0 for the incidence of anencephalus in Cork based on the voluntary notification system isid 
around $50 \%$ of the frequencies found in the Belfast, Dublin, and Galway surveys which used more than one source of ascertainment.

A genetic-environmental interaction causation model appears to be the most acceptable working hypothesis at present. Our twin data, admittedly based on small numbers, show a low concordance rate of affected twins as found by previous investigations (Yen and MacMahon, 1968). Also, the marked contrast in secular trends over periods of a generation or so, as seen, for example, by comparing the declining frequency of anencephalus in the Irish population of Boston, Massachusetts (Naggan, 1969), with the overall increases in the frequency of this defect in Belfast and Dublin since 1950 (Elwood and Warnock, 1969) argues against a predominant genetic component in causation.

For these and other reasons attention has been given to environmental agents. Recently, Renwick (1972a) suggested that a specific but unidentified substance present in potato tubers, possibly a teratogenic antibiotic induced by the potato blight fungus-Phytophthora infestans, might be a causal factor. This organism also attacks tomatoes which, like the potato, is a member of the Solanum plant genus. In contrast, Knox (1972) found a significant association between temporal variations in the incidence of anencephalus in England and Wales and the per caput consumption of nitrite-cured and cooked meats over the same time period. Statistically, this correlation with several dietary foodstuffs rather than one particular constituent is probably a confounding effect due to the habit of eating a variety of items at one meal. A similar type of problem, namely the relationship of ischaemic heart disease (IHD) to cigarette smoking and sucrose consumption, has been clarified by demonstrating that smokers have a higher sucrose intake than non-smokers; this association between sucrose and tobacco consumption produces the apparent relationship between IHD and sucrose intake (Elwood, Waters, Moore, and Sweetnam, 1970).

For 1967 annual potato consumption figures were of the order of $108,126,127$, and $158(\mathrm{~kg}$ per head) for England and Wales, Scotland, Northern Ireland, and the Irish Republic, respectively (Ministry of Agriculture 1969). During recent years, trends in consumption have been fairly steady in Britain, but there has been a decline in both parts of Ireland (Figs 1 and 2). After the 1961 epidemic of anencephalus the incidence of this defect reported from the Rotunda Hospital and the Coombe Lying-in Hospital, Dublin, also fell and a similar trend occurred in all births in Belfast. However, the association between the annual per caput potato consumption based on the three main varieties

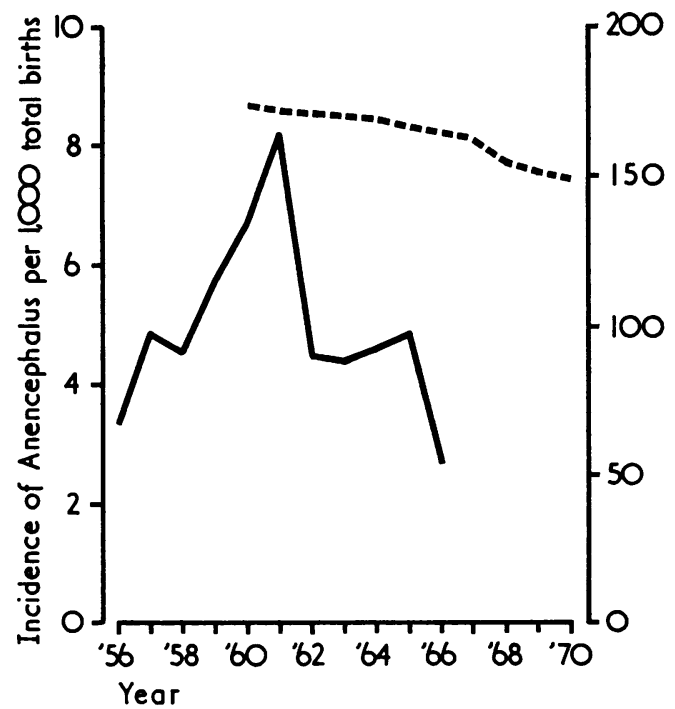

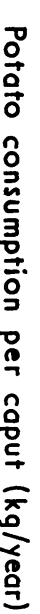

Fig. 1. Incidence of anencephalus in deliveries reported from the Rotunda Hospital plus the Coombe Lying-in Hospital, Dublin (solid line), and the per caput potato consumption ( $\mathrm{kg} /$ year) in the Irish Republic (broken line). Rank correlation coefficient between annual potato consumption $1960-65$ and anencephalic rate in the following year is +0.59 (not significant) - see text: data from Elwood (1973b and Bourke (1972).

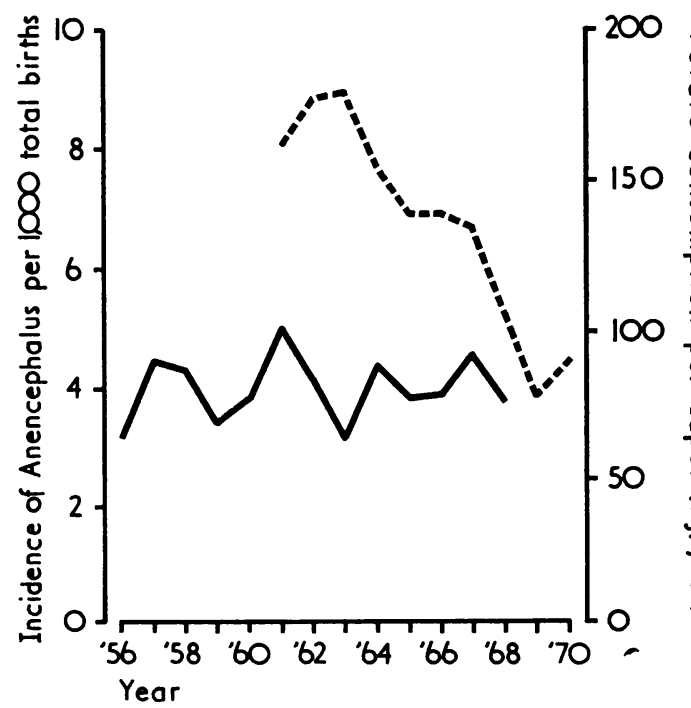

FIG. 2. Incidence of anencephalus in all (live and still) births in Belfast (solid line) and the per caput consumption (kg/year) of the three main varieties of potatoes in Northern Ireland (broken line). Rank correlation coefficient between annual potato consumption 1961-67 and anencephalic rate in the following year is- 0.01 (not significant)-see text: data from Elwood (1970a, 1972a) and Ministry of Agriculture (1972). 
(Arran Victory, Kerr's Pink, and Dunbar Standard) on sale to the general public in Northern Ireland and the Belfast anencephalic rate in the following year is not very close and is not significant where this can be measured. A similar picture is seen in relation to the data for the Irish Republic and the anencephalic rate in two large Dublin maternity hospitals. Absence of suitable data prohibits a more critical examination of these correlations based on longer time periods. However, according to Renwick (1972a), this lack of fit is not very important because, as he suggests, it is the proportion of blighted potatoes and not the total amount eaten that is the critical factor. Thus, the causal agent might operate in an all-or-none fashion rather than as a dose-related type of response. Such a conclusion possibly is more in accord with observation because some countries have a significantly higher potato consumption than Ireland, e.g. France (210 kg per head, 1966) and a lower incidence of neural tube defects (Leading article, 1972). Blight, nevertheless, seems to be prevalent in Ireland, mainly due to climatic conditions, and affects around $2 \%$ of the potato crop in a good blight year and $15 \%$ or more in a bad year. Estimates of blight severity by Cox and Large (1960) for Irish potato harvests are not very informative as almost every year is given a maximal blight score; for example, around 7 or 8 in 10 years of the decade $1947-56$ are estimated by these authors to have been "blight years' in Ireland. Also, the percentages of visibly blighted tubers at the time of a number of annual harvests as estimated for England and Wales (Renwick, 1973) are not available for Irish potato crops. However, it is known that the worst outbreak for many years occurred in 1958 (Bourke, 1972) and the 1965 crop also had an above-average infestation by the blight fungus (Ministry of Agriculture, 1966). The 1958 crop, lifted from July onwards and marketed from July through to early 1959, was accompanied by a rise in the incidence of anencephalus in Dublin in the next year and a fall in incidence in Belfast. Trends following the 1965 harvest also are inconsistent. Lastly, we note that the highest frequency of anencephalus in recent times, which occurred in 1961 in Belfast, Dublin and Scotland, was not preceded by particularly severe epidemics of potato blight.

Regarding Knox's (1972) alternative dietary hypothesis, this author attributes the correlation between the marked fall in the anencephalic rate in England and Wales and the Aberdeen typhoid fever outbreak during May and June 1964 to a decline in corned beef consumption. The Irish data (Figs 1 and 2) conform less well to this pattern. The Aberdeen typhoid outbreak was not associated with a fall at the appropriate time in the anencephalic rate in Belfast or
Dublin and we also note that the rate for Scotland 0 did not decline either. The 1966 fall in the anence- $z$ phalic rate reported from the Rotunda Hospital $\stackrel{\infty}{\circ}$ plus the Coombe Lying-In Hospital, Dublin, seems to have occurred too late to be associated with $\underset{\vec{P}}{\vec{*}}$ adverse publicity and subsequent reduction of tinned $\overrightarrow{0}$ meat consumption following the typhoid epidemic. 을 However, in the absence of data on consumption of $\frac{\bar{\sigma}}{\frac{\sigma}{2}}$ cooked meats in Dublin this point cannot be further $\stackrel{\mathbb{Q}}{\Omega}$ investigated. The social class gradient in these defects would agree more closely because cured meats are

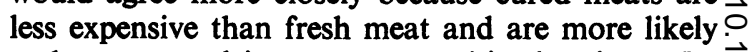
to be consumed in greater quantities by classes IV $\vec{\omega}$ and V than by classes I and II. Potatoes, on the $\stackrel{\omega}{\circ}$ other hand, are eaten in quantity daily by virtually all Irish families regardless of social class.

The reason why such high rates for both anence-. phalus and spina bifida occur in Ireland is not ${ }^{i}$ obvious. Due to the decline in many other causes of $\omega$ early mortality these defects constitute an increasing 음 problem. A potato avoidance trial, as Renwick (1972b) advocates, would test this hypothesis but another might be required to examine that proposed by Knox. As there are several difficulties in the way $\overrightarrow{0}$ of such studies it would seem prudent to designc future surveys to test several dietary hypothesesso simultaneously.

\section{SUMMARY}

All livebirths and stillbirths of 28 or more weeks'을 gestation $(41,351)$ delivered to residents of Belfast, Northern Ireland, during 1964-68 were investigatedo in order to determine the numbers resulting in anencephalus and spina bifida.

The study was conducted retrospectively and, using several sources of ascertainment, 360 cases (175 anencephalus, 185 spina bifida) were found. The combined incidence of these two major mal formations of the central nervous system, $8 \cdot 7$ per? 1,000 total births (anencephalus $4 \cdot 2$ and spina bifida $>$ $4 \cdot 5)$, is the highest recorded in any community? examined to date. Secular and seasonal trends andr the association of some selected biosocial factors were analysed for each defect separately and for both 5 defects combined. No significant secular or seasonat variations were present during the quinquenniumo studied and trends in anencephalus were similar teo those found in spina bifida.

The findings were discussed in relation to previous ${ }^{?}$ studies reported from Ireland and with respect to recent hypotheses postulating that consumption of blight-infested potatoes or nitrite-cured meats migh? play a causative role. 
We wish to thank Dr. J. McA. Taggart, Medical Officer of Health for Belfast, Dr. H. A. Warnock, Dr. K. M. Corbett and staff, Division of Maternal and Child Care, for allowing us to examine their records; the Registrar General for Northern Ireland, Professor E. A. Cheeseman, Department of Medical Statistics, and Professor J. Pemberton, Department of Social and Preventive Medicine, for assistance; Miss J. J. McMurray, Mrs. I. Hay, and Mrs. J. Russell for data preparation; and Mr. G. MacKenzie and Mr. R. McNair for statistical calculations. Also we are indebted to Professor R. K. McKee and Dr. E. L. Calvert, Department of Mycology and Plant Pathology, The Queen's University, and to Dr. P. M. Austin Bourke, Director, Meteorological Service, Dublin, for their valuable comments and expert advice.

\section{REFERENCES}

Bourke, P. M. A. (1972). Personal communication.

Cahalane, S. F., Kennedy, J. D., McNicholl, B., and O'DWYER, E. (1965). Perinatal mortality survey for County Galway, 18 months, October 1958, through March 1960. J. Irish med. Ass., 57, 135.

_- and Jessop, W. J. E. (1970). A Study of Perinatal Mortality in Ireland 1958-60. Medical Research Council of Ireland, Dublin.

Cheeseman, E. A. (1968). Medical record linkage in Northern Ireland-reconnaissance and proposals with particular reference to problems of identification. In Record Linkage in Medicine, edited by E. D. Acheson, p. 70. Livingstone, Edinburgh.

CofFeY, V. P. (1970). Spina bifida in Ireland. J. Irish med. Ass., 63, 343.

—, and Jessop, W. J. E. (1955). Congenital abnormalities. Irish J. med. Sci., Sixth Series, no. 349, p. 30. , (1957). A study of 137 cases of anencephaly. Brit. J. prev. soc. Med., 11, 174.

Corbett, K. M. (1970). Personal communication.

Cox, A. E., and Large, E. C. (1960). Potato Blight Epidemics throughout the World. Agriculture Handbook No. 174. U.S. Department of Agriculture, Agricultural Research Service, Washington.

Edwards, J. H. (1958). Congenital malformations of the central nervous system in Scotland. Brit. J. prev soc. Med., 12, 115.

Elwood, J. H. (1970a). Anencephalus in Belfast. Incidence and secular and seasonal variations, 1950-66. Brit. J. prev. soc. Med., 24, 78.

(1970b). Notification of congenital malformations in Northern Ireland, 1964-66. Med. Offr, 123, 33.

(1970c). Anencephalus in the British Isles. Develop. Med. Child. Neurol., 12, 582.

(1972a). Major central nervous system malformations notified in Northern Ireland, 1964-68. Develop. Med. Child. Neurol., 14, 731. (1972b). Potatoes and spina bifida. New Scientist, 56,602 .

(1973a). Unpublished.

(1973b). Secular trends in the incidence of major malformations of the central nervous system reported from three Dublin maternity hospitals, 1900-1965. Irish J. med. Sci., (In press).

_- and MACKENZIE, G. (1971). Comparison of secular and seasonal variations in the incidence of anencephalus in Belfast and four Scottish cities, 1956-66. Brit. J. prev. soc. Med., 25, 17.

, and Pemberton, J. (1971). Infant mortality in Belfast. Arch. Dis. Child., 46, 332.

- and Warnock, H. A. (1969). Anencephalus in Belfast and Dublin. Irish J. med. Sci., Seventh Series, 2, 17.

Elwood, P. C., Waters, W. E., Moore, S., and SweetNAM, P. (1970). Sucrose consumption and ischaemic heart-disease in the community. Lancet, 1, 1014.

General Register Office (1966). Classification of Occupations, 1966. H.M.S.O., London.

GuthKelCH, A. N. (1962). Studies in spina bifida cystica. III. Seasonal variation in the frequency of spina bifida births. Brit. J. prev. soc. Med., 16, 159.

KNox, E. G. (1972). Anencephalus and dietary intakes. Brit. J. prev. soc. Med., 26, 219.

Laurence, K. M., Carter, C. O., and David, P. A. (1968). Major central nervous system malformations in South Wales. I. Incidence, local variations, and geographical factors. Brit. J. prev. soc. Med., 22, 146.

LeAding Article (1972). Diet and congenital defects. Brit. med. J., 4, 684.

LECK, I. (1966). Changes in the incidence of neural-tube defects. Lancet, 2, 791.

- and ReCORD, R. G. (1966). Seasonal incidence of anencephalus. Brit. J. prev. soc. Med., 20, 67.

- , and Rogers, S. C. (1967). Changes in the incidence of anencephalus. Brit. J. prev. soc. Med., 21, 177.

Ministry of Agriculture (1966). Annual Progress Report on Research and Technical Work, 1965. p. 126, H.M.S.O., Belfast.

- (1969). Personal communication.

NaGgan, L. (1969). The recent decline in prevalence of anencephaly and spina bifida. Amer. J. Epidem., 89, 154.

- and MacMahon, B. (1967). Ethnic differences in the prevalence of anencephaly and spina bifida in Boston, Massachusetts. New Engl. J. Med., 277, 1119.

ReNwick, J. H. (1972a). Hypothesis: anencephaly and spina bifida are usually preventable by avoidance of a specific but unidentified substance present in certain potato tubers. Brit. J. prev. soc. Med., 26, 67. 
(1972b). Spina bifida and the potato. New Scientist, 56, 277. $1,172$.

(1973). Diet and congenital defects. Brit. med. J.,

Spellman, M.P. (1969). Anencephaly-A five year survey in Cork. J. Irish med. Ass., 62, 316.

(1970). A five year survey in Cork of spina bifida and hydrocephaly. J. Irish med. Ass., 63, 339.

Stevenson, A. C., Johnston, H. A., Stewart,M.I.P., and GoldING, D. R. (1966). Congenital malformations. A report of a study of series of consecutive births in 24 centres. Bull. Wld Hlth Org., 34, Suppl.
- and WARNOCK, H. A. (1959). Observations on the results of pregnancies in women resident in Belfast. I. Data relating to all pregnancies ending in 1957. Ann. hum. Genet., 23, 382.

WARner, W. L., Meeker, M., and Eells, K. (1957). Social Class in America: A Manual of Procedure for the Measurement of Social Status. Peter Smith, Gloucester, Massachusetts.

WARNOCK, H. A. (1969). Personal communication.

YEN, S., and MACMAHON, B. (1968). Genetics of anencephaly and spina bifida? Lancet, 2, 623. 